\title{
Conhecendo as moedas da Grécia Antiga: o projeto Sylloge Nummorum Graecorum
}

\author{
MARIA BEATRIZ BORBA FLORENZANO \\ Museu de Arqueologia e Etnologia \\ Universidade de SãoPaulo
}

RESUMO: Esta breve nota pretende apresentar o projeto Sylloge Nummorum Graecorum como um projeto de criação de um instrumento de trabalho indispensável ao pesquisador interessado nas cunhagens monetárias da Antigüidade grega.

PALAVRAS-CHAVE: Moedas gregas; numismática antiga; catálogos de moedas

Estudar as moedas antigas, dos gregos e dos romanos, é uma tarefa que pode ser tanto parte da Arqueologia quanto da História. Por um lado, nos debruçamos sobre pequenos objetos que fazem parte do que se tem chamado cultura material; de outro, somos, em boa parte das vezes, forçados a trabalhar com as inscrições, com as legendas, por vezes longas, que vêm inscritas sobre estes objetos. Objeto e texto reunidos em uma única categoria de documento têm colocado justamente a Numismática entre as disciplinas históricas, mas na fronteira com a Arqueologia. A especificidade da moeda como documento do passado das sociedades não pára por aqui. Com efeito, estamos falando de um objeto que, diferentemente de outros objetos produzidos pelo homem, foi sempre, sem exceções, fabricado em série: calcula-se que cada cunho de reverso na Antigüidade poderia produzir até 16.000 peças. Além disso, as moedas, diferentemente de outros artefatos produzidos na Antigüidade, dificilmente são encontradas em contexto arqueológico preciso já que poucas eram perdidas: hoje, os achados monetários são, na maioria dos casos, esporádicos e aleatórios, em forma de tesouros monetários que são encontrados quando da construção de fundações de edifícios ou durante o trabalho agrícola. Isto se deve ao fato de que os antigos tinham o costume de enterrar seus bens diante de algum tipo de perigo, na expectativa de recuperálos mais tarde. Como em muitos casos isto não acontecia, acabamos nós, em época moderna, por recuperar estes pequenos ou grandes conjuntos de moedas.

Esta especificidade da moeda provocou o desenvolvimento de uma metodologia independente que pudesse potencializar este objeto como documento que informa sobre as sociedades do passado; e assim a Numismática tornou-se uma especialidade, constituindose num campo de estudos próprio. 
De sorte a recompor as séries monetárias, os grandes conjuntos de emissões, e recuperar os traços da circulação de moedas, a Numismática se fundamenta em estudos muito minuciosos dos pesos das peças (metrologia) e da tipologia das imagens monetárias (caracteroscopia); fundamenta-se também nas análises físicas e químicas dos metais empregados em sua fabricação (metalografia) e na pesquisa sobre a composição e a distribuição geográfica dos tesouros monetários. Moedas da mesma tipologia e metal são pesadas individualmente e seus pesos jogados em grandes quadros estatísticos; imagens monetárias são comparadas individualmente na procura da identificação de cada cunho empregado na produção de séries, na expectativa de definir o volume das emissões; os metais são analisados com a finalidade de se conhecer os sistemas bimetálicos (ou trimetálicos) e as proporções dos valores atribuídos a cada denominação monetária. Tudo isso se realiza visando conhecer o papel desempenhado pela moeda em uma sociedade: o objetivo em se emitir moedas, a sua importância em um sistema de valores específico, o seu uso no grande ou no pequeno comércio.

Neste contexto, em que cada peça é valorizada individualmente, para se conhecer a natureza do conjunto maior, o catálogo detalhado de espécimes é extremamente valorizado como instrumento indispensável do trabalho do pesquisador. No caso das coleções monetárias, desde o século XVI, na Renascença, procurou-se publicar listagens de moedas seja como forma de registro das coleções que então se formavam, seja como maneira de conhecêlas melhor. A idéia de um corpus nummorum foi, com efeito, lançada por primeira vez por Wolfgang Lazius, um médico vienense que escreveu em 1558 o seu Commentatiorum Vetustarum Numismatum. No final do século XVIII, foi Joseph H. Eckhel que finalmente organizou um repertório geral em que moedas gregas e romanas aparecem classificadas e ordenadas da maneira como até hoje o fazem os modernos catálogos. No século XIX, época em que as disciplinas que conhecemos hoje se constituíram e que, no caso da Arqueologia, se montaram os grandes corpora de artefatos e documentos, também as moedas mereceram catálogos, agora em forma de listagens mais completas, mas nem sempre com cada peça individualizada. Veja-se, por exemplo, o catálogo do Museu Nacional de Nápoles, elaborado por G. Fiorelli (1866 e1870), o de Ettore Gabrici, das moedas de bronze do Museu de Palermo, o de Dressel, do Museu Real de Berlim (1894), e o mais famoso de todos, o catálogo de moedas gregas do Museu Britânico, em 29 volumes, publicado entre as duas últimas décadas do século XIX e a primeira do século XX.

O desenvolvimento da disciplina Numismática, no entanto, e a utilidade que demonstraram ter os catálogos de moedas, no sentido de agrupar e sistematizar a documentação monetária conservada nos diversos Gabinetes Numismáticos, fez com que a Comissão Internacional de Numismática - organismo criado para estimular os estudos sobre as moedas - propusesse um projeto único de publicação padronizada de catálogos de moedas gregas. Este projeto teve início nos anos 30 e desde então numerosas coleções públicas de moedas gregas, de diferentes países, vêm sendo publicadas na série Sylloge Nummorum Graecorum.

Este é, hoje, um projeto internacional, patrocinado tanto pela Comissão Internacional de Numismática quanto pela União Acadêmica Internacional. Com volumes de formato padronizado, com informações atualizadas e bibliografia correspondente, cada publicação 
procura apresentar as moedas com todos os dados indispensáveis ao seu estudo: além da reprodução fotográfica de cada peça, o catálogo traz a descrição de cada moeda, o seu peso, a direção das imagens de anverso em relação ao reverso, o registro do metal em que a moeda foi fabricada. Deste projeto participam grande parte dos países da Europa Ocidental, a Romênia e, na América, os Estados Unidos e, desde 1982, o Brasil. Pretende-se, assim, tornar acessível à comunidade científica internacional, para fins de estudo, as diferentes coleções de moedas gregas.

Há no Brasil uma coleção de aproximadamente 2.500 moedas gregas espalhadas em vários Museus: Museu de Arqueologia e Etnologia e Museu Paulista, da Universidade de São Paulo; Museu Histórico Nacional, do Rio de Janeiro; Museu Numismático do Estado do Amazonas, em Manaus; Museu do Banco do Brasil, no Rio de Janeiro, e Museu de Valores do Banco Central, em Brasília. São coleções que possuem peças importantes e que, sem serem inéditas, pois, como já ficou dito acima, as moedas foram sempre fabricadas em série, são acrescentadas ao conjunto de peças conhecidas, permitindo o conhecimento mais completo das diferentes emissões de moedas antigas. Entre estas 2.500 moedas há desde as mais antigas, datadas do século VII e VI a.C., provenientes da Lídia na Ásia Menor, até aquelas produzidas por cidades gregas que bateram moedas já sob o domínio romano. Entre elas podemos encontrar moedas de todas as denominações: desde as unidades monetárias como a dracma ateniense até a pequena fração do hemióbolo, moeda tão pequenina que não resiste ao sopro. Há também moedas nos vários metais que os antigos usaram para cunhar suas peças: a prata e o ouro e as diferentes ligas metálicas que, em Numismática, denominamos genericamente de bronze. São todas peças guardadas em gavetas e que, sem dúvida, merecem um manuseio de sorte a transformarem-se em verdadeiros documentos que informem sobre as sociedades que os produziu.

O projeto Sylloge Nummorum Graecorum envolve não apenas a identificação, pesagem e descrição minuciosa de cada moeda; é preciso ainda um exame acurado de sua autenticidade. Não me refiro aqui às falsificações contemporâneas à moedagem da própria peça falsificada que foram feitas - presumimos - com a finalidade de se obter algum ganho pecuniário ou em resposta à falta de numerário em circulação, mas, sim, às falsificações de moedas antigas para fins colecionísticos, procedimento comum já desde a Renascença pelo menos. As peças falsificadas dessa forma são descartadas do catálogo enquanto as falsificações de época devem ser devidamente identificadas e registradas.

Há, ainda, uma fase do trabalho que deve ser mencionada entre a descrição da moeda para o seu registro neste catálogo e a sua reprodução fotográfica: a da moldagem de cada moeda. O relevo da maioria das moedas gregas antigas é muito gasto impedindo que a sua reprodução seja perfeita. Além disso, boa parte delas é escura, como no caso das moedas de bronze e mesmo das de prata, que nem sempre são passíveis de limpeza. Assim, o ideal é a elaboração de um molde, feito em plastelina, a partir de cada uma das faces da moeda e em seguida a realização da moldagem obtida em gesso a partir do molde. Essas moldagens, feitas em gesso preferencialmente de cor clara, tornam-se, elas mesmas, documentos na medida em que reproduzem fielmente as imagens de cada moeda e podem ser muito melhor fotografadas para a finalidade do catálogo. 
Uma última reflexão a respeito da consecução de um projeto como o da Sylloge Nummorum Graecorum merece ser destacada. Na verdade, qual o futuro deste tipo de publicação em um mundo informatizado como o nosso? Sabemos que inúmeros Museus e Gabinetes numismáticos possuem ao menos uma parte de suas coleções informatizada. Não seria, com efeito, muito mais racional partir desde já para um tipo de publicação que pudesse ser facilmente acessível pela rede? Ao mesmo tempo em que sabemos que a resposta é afirmativa, sabemos também que há inúmeros problemas que não foram ainda resolvidos em termos das redes informatizadas. Um deles é, sem dúvida, a dificuldade enfrentada por muitos Museus em lidar com a questão dos direitos autorais sobre os acervos que conservam. Outro problema é a falta de padronização na classificação e sistematização adotada por cada Museu. Na maioria das vezes, as coleções numismáticas encontram-se preservadas em Instituições que abrigam vários tipos de objetos e assim a classificação atende às suas coleções em geral e não exclusivamente às coleções de moedas. Assim, principalmente por estas razões de ordem prática, acreditamos que ainda estamos distantes do abandono da publicação destes volumes tradicionais de catálogos da série Sylloge Nummorum Graecorum. Eles ainda são o principal instrumento de trabalho daqueles interessados em aproveitar as informações fornecidas pelas moedas para o conhecimento das sociedades antigas.

\section{Referências bibliográficas}

CLAIN-STEFANELLI, E. Numismatics: an ancient science. Contributions from the Museum of History and Technology, Bulletin, 229, Washington D.C., 1965.

COSTILHES, A. J. O que é Numismática? São Paulo: Brasiliense, 1988.

FRÈRE, H. Numismática. Uma introdução aos métodos e à classificação. Trad. e adaptação de Alain Costilhes e de Maria Beatriz Borba Florenzano. Louvain-la-Neuve: Séminaire de Numismatique Marcel Hoc -UCL, 1984.

FLORENZANO, Maria Beatriz Borba. Ancient Greek coins in Brazil: the Sylloge Nummorum Graecorum. Classica, São Paulo, 13/14, p. 405-408, 2000/2001.

ABSTRACT: This note intends to present the series Sylloge Nummorum Graecorum as the main tool in the work of the researcher interested in ancient Greek coinage.

KEYWORDS: Greek coinage; ancient numismatics; coin catalogues. 